\title{
Cell motility driving mediolateral intercalation in explants of Xenopus
}

\section{laevis}

\author{
JOHN SHIH* and RAY KELLER
}

Division of Cell and Developmental Biology, Department of Molecular and Cell Biology, University of California, Berkeley, Berkeley, CA 94720, USA

*Present Address: Beckman Institute, California Institute of Technology, Pasadena, CA

\section{Summary}

In Xenopus, convergence and extension are produced by active intercalation of the deep mesodermal cells between one another along the mediolateral axis (mediolateral cell intercalation), to form a narrower, longer array. The cell motility driving this intercalation is poorly understood. A companion paper shows that the endodermal epithelium organizes the outermost mesodermal cells immediately beneath it to undergo convergence and extension, and other evidence suggests that these deep cells are the most active participants in mediolateral intercalation (Shih, J. and Keller, R. (1992) Development 116, 887-899). In this paper, we shave off the deeper layers of mesodermal cells, which allows us to observe the protrusive activity of the mesodermal cells next to the organizing epithelium with high resolution video microscopy. These mesodermal cells divide in the early gastrula and show rapid, randomly directed protrusive activity. At the early midgastrula stage, they begin to express a characteristic sequence of behaviors, called mediolateral intercalation behavior (MIB): (1) large, stable, filiform and lamelliform protrusions form in the lateral and medial directions, thus making the cells bipolar; (2) these protrusions are applied directly to adjacent cell surfaces and exert traction on them, without contact inhibition; (3) as a result, the cells elongate and align parallel to the mediolateral axis and perpendicular to the axis of extension; (4) the elongate, aligned cells intercalate between one another along the mediolateral axis, thus producing a longer, narrower array. Explants of essentially a single layer of deep mesodermal cells, made at stage 10.5 , converge and extend by mediolateral intercalation. Thus by stage 10.5 (early midgastrula), expression of MIB among deep mesodermal cells is physiologically and mechanically independent of the organizing influence of the endodermal epithelium, described previously (Shih, J. and Keller, R. (1992) Development 116 887-899), and is the fundamental cell motility underlying mediolateral intercalation and convergence and extension of the body axis.

Key words: gastrulation, Xenopus, cell motility, protrusive activity, cell alignment, cell intercalation, morphogenesis.

\section{Introduction}

In this paper, we describe the cell motility that produces mediolateral cell intercalation, the principal cell behavior driving convergence and extension of the axial mesoderm of Xenopus embryos (Wilson et al., 1989; Keller et al., 1989a; Wilson and Keller, 1991). Convergence and extension of the dorsal tissues in early embryos is a major morphogenetic process in formation of the vertebrate body plan. Dorsal mesodermal, endodermal and neural tissues narrow towards the dorsal midline (convergence) and lengthen along the anterior-posterior axis (extension) during gastrulation and neurulation (Vogt, 1929; Keller, 1975, 1976). In amphibians, convergence and extension occur autonomously and specifically in the prospective notochord, somitic mesoderm and neural plate (Spemann, 1938; Schechtman, 1942; Keller and Danilchik, 1988; Keller, 1986; Jacobson and Gordon, 1976; Keller et al., 1992a). Convergence and extension play major roles in gastrulation
(Schechtman, 1942; Keller, 1986; Keller et al., 1991a,b) and in neurulation (Jacobson and Gordon, 1976; Jacobson, 1981; Jacobson et al., 1986; Schoenwolf and Alvarez, 1989; Keller et al., 1992a,b). In mesodermal tissues (Wilson et al., 1989; Wilson and Keller, 1991; Keller and Tibbetts, 1989) and in neural tissues (Keller et al., 1992a,b), convergence and extension occur in two separate but overlapping phases. First, thinning and extension occur by radial intercalation of several layers of deep cells to form fewer layers of greater area. Then convergence and extension occur by mediolateral intercalation of cells to form a longer, narrower array. In addition to their morphogenetic function, these cell intercalations participate in patterning the early embryo because they change the geometry of tissues and thus alter the consequences of tissue interactions (see Keller et al., 1991a,b; 1992a,b; Shih and Keller, 1992a,b). Radial and mediolateral cell intercalations occur during axial elongation in other chordates, including fish (see Warga and Kimmel, 1990; Trinkaus et al., 1991, 1992), 
birds (Schoenwolf and Alvarez, 1989) and ascidians (see Miyamoto and Crowther, 1985), and function in a variety of morphogenetic processes throughout the Metazoa (Keller, 1987).

Despite the importance of these cell intercalations, the motility, protrusive activity and contact behavior underlying them have not been studied directly until recently (Keller and Tibbetts., 1989; Keller et al., 1989a, 1991a,b; Trinkaus et al., 1991, 1992), principally because these events are hidden from view within complex tissues. Discovering their mechanism is a major opportunity and challenge in establishing the cellular basis of morphogenesis. Thus we developed the 'open-faced' explant system (Keller et al., 1985a,b), in which the dorsal marginal zone (DMZ) of the Xenopus gastrula is explanted and cultured under conditions that expose to observation, video recording and experimental manipulation the deep mesodermal cells that drive convergence and extension. Using this system, we described the radial and mediolateral cell intercalations driving convergence and extension during gastrulation (Wilson and Keller, 1991) and neurulation (Wilson et al., 1989; Keller et al., 1989a, 1992a). Time-lapse video microscopy of fluorescently labelled cells in explants revealed the motility driving mediolateral intercalation in the notochord of the neurula stages (Keller et al., 1989a). But analysis of the innermost mesodermal cells, the ones exposed in open-faced explants, did not reveal a pattern of cell motility that we could envision driving mediolateral intercalation during gastrulation (Wilson and Keller, 1991). Meanwhile several facts suggested that the motility driving mediolateral intercalation during gastrulation is displayed most strongly by the outermost mesodermal cells that lie immediately beneath the endodermal epithelium. First, these deep mesodermal cells are bipolar, elongated mediolaterally and have large medial and lateral protrusions (Keller et al., 1989b), a morphology associated with mediolateral cell intercalation in the notochord of the neurula (Keller and Tibbetts, 1989). Second, a companion article (Shih and Keller, 1992a) shows that the dorsal endodermal epithelium of the early gastrula marginal zone can organise convergence and extension of deep mesodermal cells from the ventral side of a normal embryo or from ventralised embryos, neither of which would normally converge or extend. Third, the endodermal epithelium is required until midgastrula stage for the mesodermal cells to converge and extend. These results suggest that the cell behavior driving mediolateral intercalation is induced in and displayed first and most strongly among the mesodermal cells immediately beneath the endodermal epithelium, the apparent source of the inducing signals.

We devised two new explants to visualize the mesodermal cells immediately beneath the endodermal epithelium. The 'shaved' open-faced explant, is made by shaving off the inner layers of deep cells of an open-faced explant, leaving one or several layers of deep mesodermal cells on the inner surface of the endodermal epithelium (Fig. 1A). The 'deep cell' explant consists of deep mesodermal cells alone, explanted at stage 10.5, without the overlying endodermal epithelium. Both explants have allowed us to see the protrusive activity driving mediolateral intercalation.

\section{Materials and methods}

\section{Preparation of embryos and solutions; microsurgery and explantation}

Xenopus laevis eggs were ovulated, fertilized and dejellied by standard methods (see Kay and Peng, 1991). For labelling with fluorescein dextran (FDX) during the first cell cycle, the embryos were placed in $4 \%$ ficoll solution in $100 \%$ MNT solution and injected with 10-15 $\mathrm{nl}$ of FDX10,000 (Sigma) at $25 \mathrm{mg} / \mathrm{ml}$ of 0.2 $\mathrm{N} \mathrm{KCl} \mathrm{(Gimlich} \mathrm{and} \mathrm{Braun,} \mathrm{1985).} \mathrm{Explants} \mathrm{were} \mathrm{cultured} \mathrm{in} \mathrm{Shih-}$ modified Danilchik's (SMD; see Keller, 1991). 'Shaved' explants of the DMZ were made like standard open-faced explants of the early gastrula (Wilson and Keller, 1991), using a knife of eyelash hair and a hairloop. Two or three of the deepest layers of mesodermal cells were then 'shaved' off as shown in Fig. 1A. The number of layers of deep cells can be reduced to one layer of mesoderm cells and a single layer of suprablastoporal (endodermal) epithelium. When one layer of deep cells remains, the involuting marginal zone (IMZ) region appears gray in color and a contiguous pavement of epithelial cells can be seen through the spaces between the deep cells. Deep cell explants were made by excising the dorsal sector of the stage 10.5 gastrula with cuts about 45 degrees on both sides of the dorsal midline, as described for the open-faced explant (Wilson and Keller, 1991). The involuted tissue was then pulled back from its involuted position and straightened such that it lies in the same plane as the uninvoluted tissue. The epithelial layer was then peeled off with an eyelash hair, and the remaining deep cells were cultured as described previously (Wilson and Keller, 1991).

For low-light fluorescence video recording, the suprablastoporal endoderm of an embryo previously labelled with FDX was peeled back, and a small number of labelled cells were grafted from the underlying presumptive chordamesoderm to the same position among the corresponding unlabelled deep cells of a shaved explant. For epi-illumination and bright-field optics, the shaved explants were held open by pressing each between the lid of a standard $35 \mathrm{~mm}$ Falcon tissue culture dish and a narrow piece of coverslip supported with Dow Corning High Vacuum Grease on the ends, as described previously (Wilson and Keller, 1991). For high resolution fluorescence microscopy, a hole was cut in the bottom of the culture dish and a number 1.5 glass coverglass was glued across it.

\section{Time-lapse video microscopy with epi-illumination and low-light fluorescence}

Time-lapse recordings of cell behavior under epi-illumination were made using a Zeiss compound microscope and a DAGEMTI 81 high resolution video camera. Images were processed, using frame averaging (16 frames), background subtraction and edge enhancement, with an Image One video image processor (Universal Imaging, Media, PA), and recorded on a Panasonic TQ2028F optical memory disk recorder (OMDR). Low-light fluorescence recordings were made with a Hamamatsu C2400-08 silicon intensified target (SIT) camera, using the same image processing program. Labelled explants were illuminated with a 12 volt, 100 watt halogen bulb with intensity controlled with a Nikon UN transformer. The duration of illumination was regulated by a Uniblitz model D122 shutter (Vincent Associates), controlled by the image processor. An inverted Nikon Diaphot microscope and $10 \times, 20 \times$ and $60 \times$ fluorescence objectives were used.

\section{Antibody staining and cell behavioral analysis}

Whole-mount staining of somitic tissue was done according to the protocol of Wilson (Wilson, 1990; see Keller, 1991), using the monoclonal antibody 12-101 (Kintner and Brockes, 1984) from the NIH Developmental Biology Hybridoma Bank. Frequency of 
protrusive activity was measured from low-light recordings by counting new protrusions per unit time. A new protrusion is one forming in a new position, in a new direction, or renewed advance of a previously inactive protrusion. To describe the direction of protrusions, they were plotted as falling into one of 18 sectors of 20 degrees each around the cell perimeter, with $90^{\circ}$ and $270^{\circ}$ representing medial and lateral positions. Cell shapes were traced from images on the video monitor and digitized on a Summasketch graphics tablet (Summagraphics, Inc.). Area, length-width ratio and axial orientation were measured using Mac Morph 1.1 software, modified by Jeff Hardin from MacMeasure 1.6, a publicdomain morphometrics program written by Wayne Rasband, Research Services Branch, National Institutes of Mental Health, Bethesda, MD 20892. Student's $t$-test was used to compare means of cell shape parameters. The extension index is the original distance between cells along the anterior-posterior axis (the axis of extension) divided into the distance between them at a later stage. The convergence index is determined in the same manner but along the mediolateral axis. The mediolateral intercalation index was determined by identifying and counting the cells forming a continuous column lying parallel to the prospective anterior-posterior axis. These identified cells were traced to a later stage by time-lapse recording and then connected to one another by identifying and counting the intervening cells, which have intercalated, taking the shortest route possible to reach the next cell in the original column. This number was added to the original number of the cells in the column, and then the total was divided by the original number in the column to give the mediolateral intercalation index.

\section{Results}

\section{Overview of the development of 'shaved' explants}

Shaved explants converge and extend less than normal open-faced explants, usually attaining a fourth to a half the extension of open-faced explants (Fig. 1B). The vegetal ends of the explants protrude with extension and the lateral margins indent with convergence (arrows, Fig. 1B), transforming the rectangular explants into bullet-shapes. In the shaved explant, as in the standard open-faced explant, the notochord-somite boundary appears between stage 11.5 and stage 12, segregating a medial notochord from somitic mesoderm on both sides (Fig. 1B). The notochord forms its characteristic array of elongated cells, oriented parallel to one another and perpendicular to the long axis of the notochord (Fig. 1C). By the late neurula (stage 17-20), the somitic mesoderm undergoes segmentation, poorly in explants showing little extension and well in explants showing greater extension (Fig. 1D). Whether or not segmentation occurs, somitic tissue is identified by staining with the 12-101 somite-specific antibody (Fig. 1E). As in open-faced explants (Wilson and Keller, 1991), the dorsal noninvoluting marginal zone (DNIMZ), consisting of prospective neurectoderm, does not extend in shaved explants (Fig. 1B). Shaved explants are typically very thin, consisting of epithelial endoderm, a layer of somitic mesoderm and a notochord, which often thickens secondarily as its cells swell up during vacuolation (Fig. 1F,G). The amount of convergence and extension of shaved explants can be decreased from near that of normal open-faced explants to nearly none by increasing the pressure applied by the restraining coverslip, thus increasing friction, or by reduc- ing the number of layers of deep cells, which produce the forces for convergence and extension (see below).

Explants showing little convergence and extension develop trapezoidal notochords, narrower at the vegetal (prospective anterior) end than at the animal (prospective posterior) end (Fig. 2A). Without any convergence and extension, the notochord shape resembles that of the notochord fate map (Keller, 1976) and the shape of the notochord in early gastrula explants deprived of endodermal epithelium, which also converge and extend very little (Wilson, 1990). In explants that converge and extend well, the notochord boundaries come to lie nearly parallel to one another (Fig. 2B), as they do in open-faced explants (Wilson and Keller, 1991), in sandwich explants (Keller and Danilchik, 1988) and in whole embryos (Keller and Tibbetts, 1989), but the notochords in explants always remains broader along their full length (Fig. 2B) than those in the embryo (see Keller and Tibbetts, 1989). The notochord cells in shaved explants have the mediolaterally elongated shape and arrangement seen in embryos (see Keller et al., 1989a).

\section{Cell division within the prospective chordamesoderm of shaved explants}

The deep mesodermal cells on the inner surface of the shaved explant of a stage 10 (early gastrula) explant are large and isodiametric (Fig. 3A,B). Most of these cells divide in the first half of gastrulation and very few divide in the second half. Since the explants generally have one layer of deep cells, we can analyze cell division directly by video recording. In the first half of gastrulation, covering 2 hours from stage 10 to $10.5,80 \%$ of the mesoderm cells divide once and $5 \%$ divide twice (40\% per hour and $2.5 \%$ per hour respectively). In the second half of gastrulation, covering 2 hours from stage 10.5 to 12 , only $2 \%$ divide (Fig. 4). We found no apparent correlation between when a cell divided and either its mediolateral or animal-vegetal position. There was no apparent difference in the mitotic frequency or pattern in explants that extended well and those that extended poorly.

\section{Radial intercalation}

The radial intercalation seen in open-faced explants in first half of gastrulation should not occur in shaved explants having one layer of deep cells. Nevertheless, some was observed, probably because local regions temporarily become two-layered. The daughters of the single round of cell division before stage 10.5 usually change in shape such that they still occupy one layer; however, some repack to form two layers, accounting for the cells leaving the observed layer, and generating a hidden population that could later reappear. In addition, many of the $20 \%$ of the cells not seen dividing in the early part of gastrulation may divide with the spindle oriented perpendicular to the surface of the explant, making 'two layers' of cells with one of the daughters concealed by the other, again generating a second, unseen layer of mesodermal cells. From stage 10 to stage 10.5 , previously unseen cells entered the observed surface of the explant at a rate of $10 \%$ per hour and disappeared at $6 \%$ per hour. During the late phase (stage 10.5 to stage 12 ), these parameters were $10 \%$ and $3 \%$ per hour, 
A
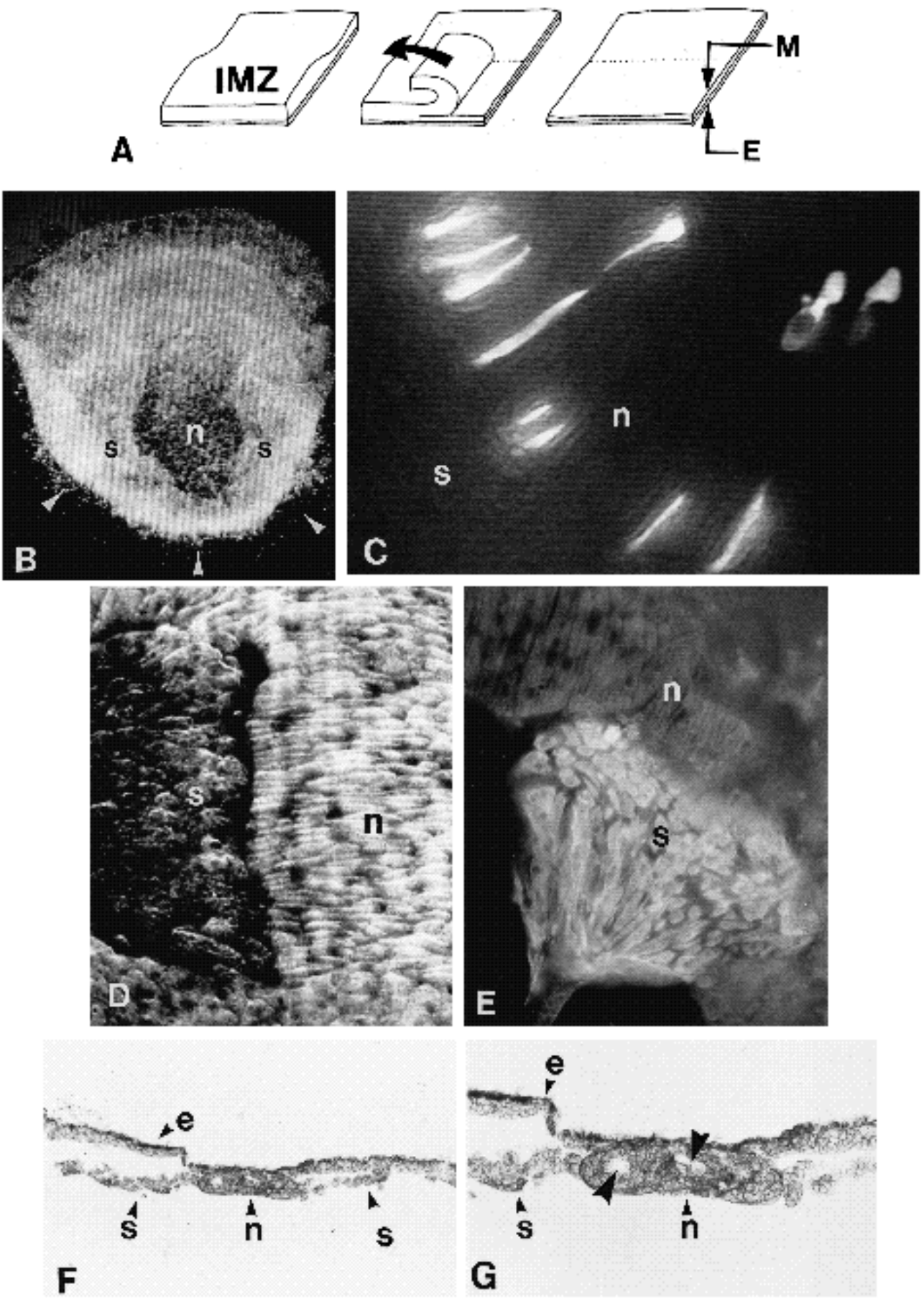

Fig. 1. (A) Shaved explants were made by preparing standard open-faced explants from a stage 10 embryo (left), and then 'shaving' two or three of the deeper mesodermal cell layers off the vegetal end of the explant (the involuting marginal zone, IMZ) with an eyelash hair (arrow, middle), leaving one or two layers of prospective mesodermal cells (M) remaining on the inner surface of the endodermal epithelium (E). Between stage 10 and 12, shaved explants converge and extend but less than normal sandwich explants. Convergence and extension are expressed as indented sides and a protruding, rounded vegetal end (pointers, B) as opposed to the squared-off profile of the original. The notochord (n) forms centrally in the IMZ portion of the explant and vacuolates by stage 26. Somitic mesoderm (s) differentiates on both sides of the notochord (B). FDX-labelled deep cells were seeded onto the inner surface of an unlabelled explant and their behavior documented with low-light fluorescence microscopy and video recording for periods of up to 10 hours $(\mathrm{C})$. A micrograph from a recording of a stage 18 shaved explant (C) shows FDX-labelled cells in the notochord (n), having differentiated the parallel array of transversely elongated cells, unique to the notochord (see Keller et al., 1989a). Somitic mesoderm (s) usually segments poorly in the monolayer of deep cells in shaved explants (D), but its differentiation is indicated by staining with the somite-specific monoclonal antibody 12-101 (E). A $10 \mu \mathrm{m}$ thick cross-section of a shaved explant at stage 28 (F) shows the somitic mesoderm (s), the notochord (n) and the endodermal epithelium (e). Note that the endoderm and somitic mesoderm are often pulled apart as the fixed explant is extracted from the culture chamber. A higher magnification (G) shows vacuoles (large pointers) in the notochord, which swell and thicken the notochord later in development. The vegetal ends of the explants are at the bottom in $\mathrm{B}$ and $\mathrm{D}$ and at the lower right in C and D. Magnification: B - 23×; C,D,E and G - 78×; F - 39x. 


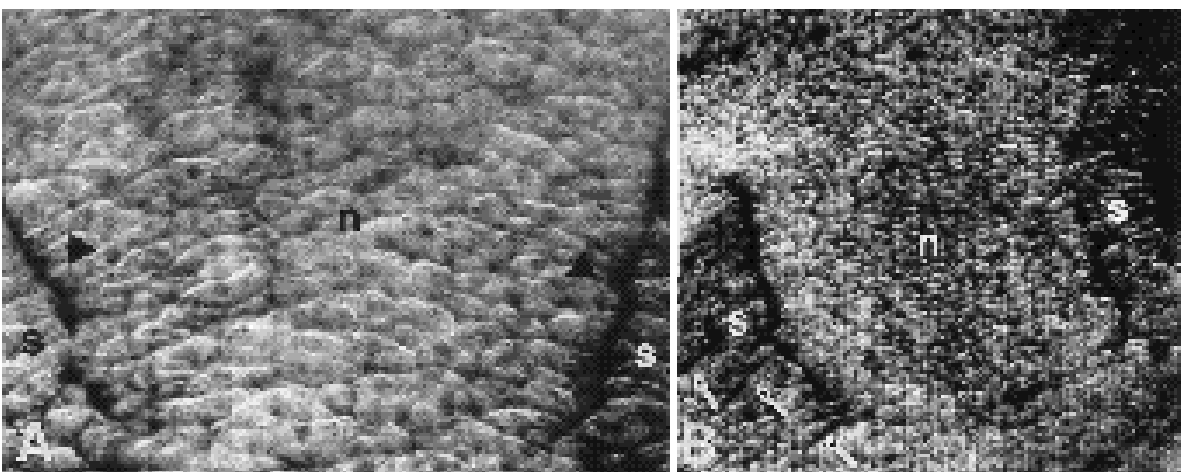

Fig. 2. When the notochord-somite boundaries first appear (pointers) in shaved explants that show minimal convergence and extension, they define a trapezoidal notochord, narrower at the vegetal end (A). Note that the notochord cells are elongated and aligned parallel to one another and transverse to the prospective anterior (bottom) to posterior (top) axis of the notochord, a process that begins anteriorly and passes posteriorly, and progresses medially from the lateral boundary (see Shih and Keller, 1992b). The overall length of the prospective notochord is initially about 10-15 cells. In shaved explants that converge and extend more, the notochord-somite boundaries are more parallel and the overall length of the notochord is greater (B). The flanking somitic mesoderm shows more frequent and more regular segmentation in extending explants (arrows, B). Magnification: A - 84×; B - 42×.
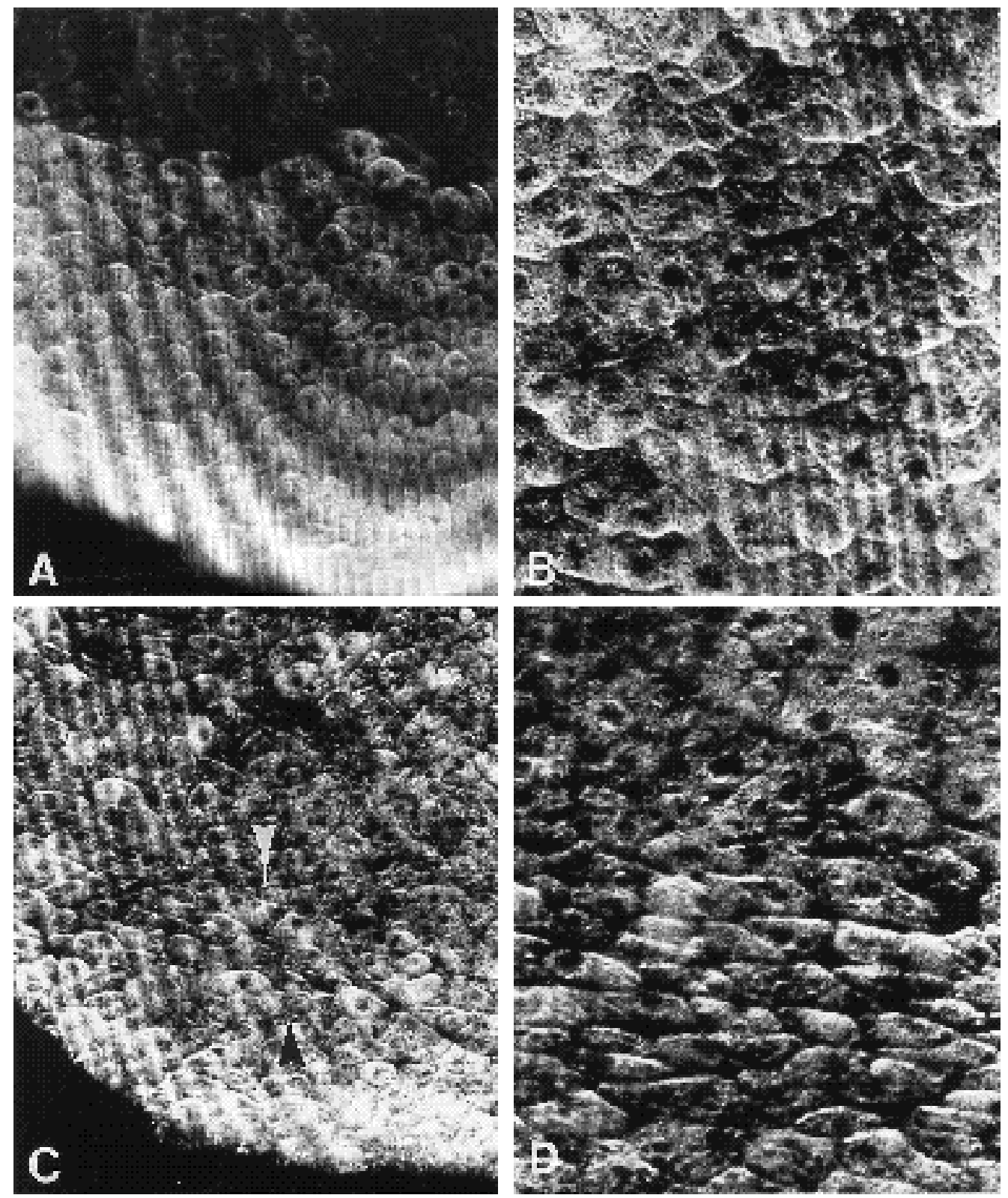

Fig. 3. A micrograph from a video recording of a shaved explant shows the appearance of deep mesoderm cells of the IMZ at stage 10 (A). Higher magnification shows these cells to be rounded, nearly isodiametric and displaying no visible signs of polarity (B). By stage 10.5 , the size of these cells is reduced ( $c f$. $\mathrm{C}$ and $\mathrm{A}$ ), in part because of one round of division. The vegetal alignment zone (VgAZ) is first discernible beginning about 4 cells animalward from the vegetal margin (pointers, C). Higher magnification of the cells in the VgAZ shows the characteristic elongation and alignment of the cells parallel to the mediolateral axis (D). Vegetal is at the bottom and animal at the top of all illustrations. magnification: A,C - 80x; B,D - 160×. 


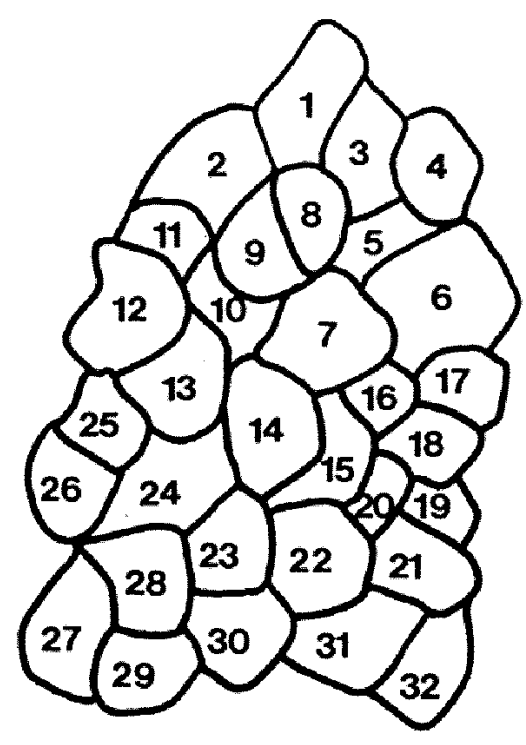

Stage 10

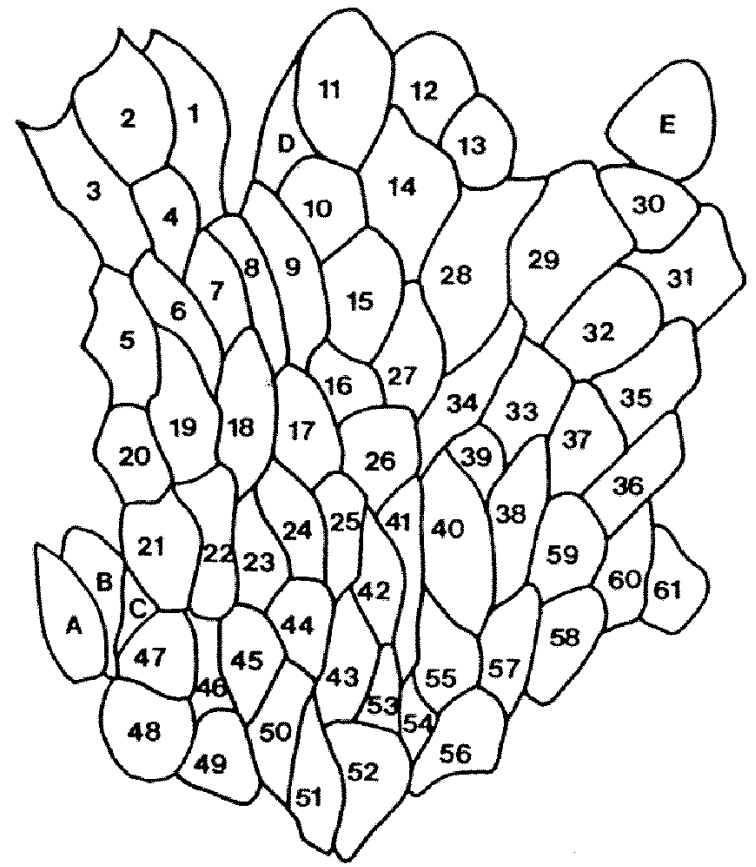

Stage 10.5

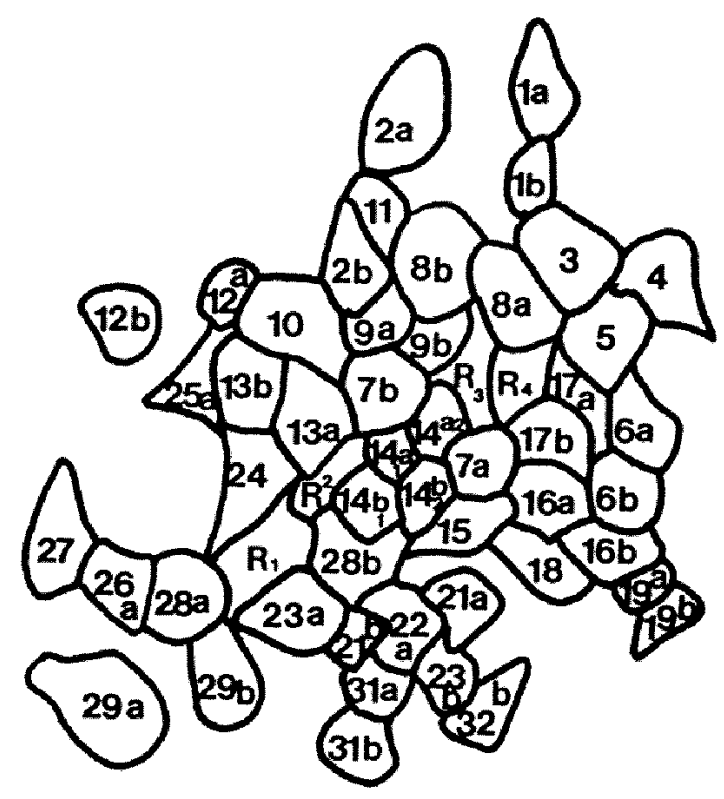

Stage 10.5

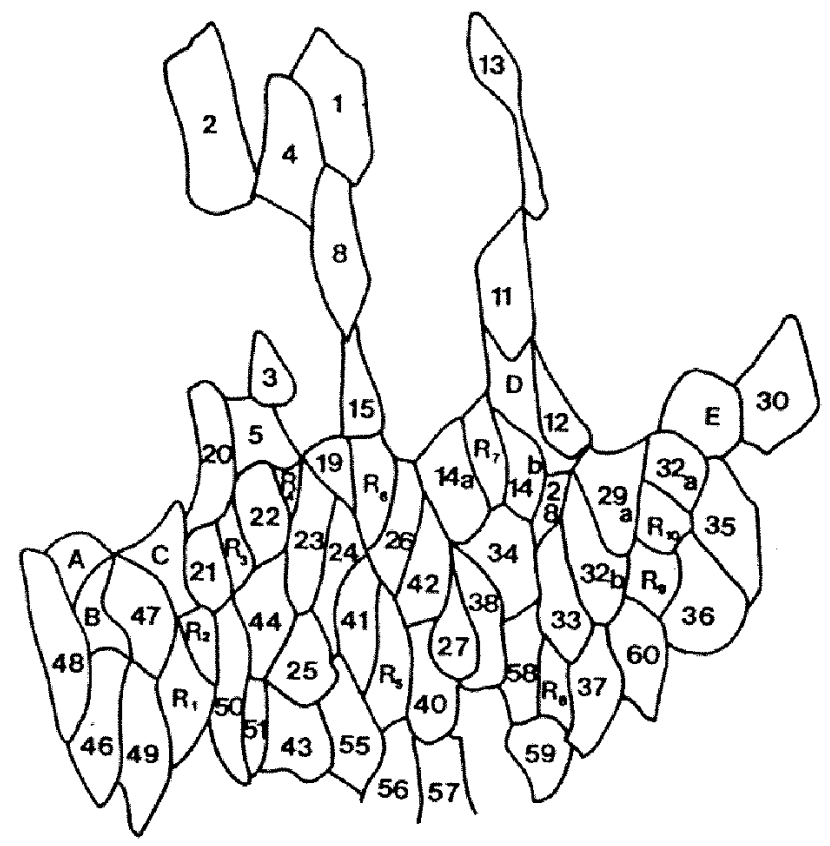

Stage 12

Fig. 4. Tracings of cells from video recordings show outlines of cells in shaved explants over a 2 hour period from stage 10 to stage 10.5 (top panel) and over another 2 hours from stage 10.5 to 12 (bottom panel) in an explant showing little extension. The vegetal end (prospective anterior) is to the left and the animal end (prospective posterior end) is to the right in all cases.

respectively. Decreasing coverslip pressure and allowing greater convergence and extension changed these rates slightly but not differentially, with $15 \%$ per hour leaving and $9 \%$ per hour entering in the early phase and $13 \%$ an hour entering and $9 \%$ an hour leaving the observed layer in the late phase. The increased convergence and extension 
in these explants is not due to changes in radial intercalation but to more effective mediolateral cell intercalation. Radial intercalation appeared randomly over the explant and the participating cells do not appear to comprise a specialized subpopulation.

Neither cell division nor radial intercalation significantly changes the area of the inner surface of the explant. In the early phase, areas of individual cells on the observed surface of the explants decreased by about $45 \%$ while their number nearly doubled. Thus, the total surface area occupied by these cells and their progeny remained essentially constant. Most daughter cells remain in a single plane and change shape, becoming taller and roughly halving the area that they present at the inner surface of the explant. Later, between stage 10.5 and stage 12 , when divisions all but cease, the mean cell surface area also remained essentially constant, changing by less than $1 \%$. In contrast, standard open-faced explants increase in area; the cell surface area remains constant at about $1000 \mu \mathrm{m}^{2} /$ cell but more cells are added by division and radial intercalation (Wilson and Keller, 1991).

\section{Development and function of mediolateral intercalation behavior}

By the beginning of stage 10.5, the mesodermal cells begin a sequence of motile behaviors that normally result in mediolateral intercalation, and thus we call this complex mediolateral intercalation behavior (MIB). However, MIB does not always result in mediolateral intercalation; the expression of MIB indicates that the participating cells are attempting to intercalate but they may not be sucessful, depending on the mechanical resistence offered to convergence and extension. MIB begins at the vegetal end of the explant, in a region called the vegetal alignment zone (VgAZ), and from there spreads across the mesoderm in anterior-to-posterior and lateral-to-medial progressions that are described a companion paper (Shih and Keller, 1992b). Here we describe the behaviors comprising MIB as they are expressed the $\mathrm{VgAZ}$, and in the anterior notochordal mesoderm that forms from the $\mathrm{VgAZ}$. This description applies as well to the later progression of these behaviors in the somitic and notochordal mesoderm (Shih and Keller, 1992b).

\section{(1) Cell elongation and alignment}

Between stage 10 and stage 10.5, the deep mesodermal cells are generally cubical before and after cell division (Figs $3 \mathrm{~A}, \mathrm{~B}, 4$, top panel). On the basis of morphometric analysis of four recordings, their average length/width ratio (LWR) at stage 10 was $1.48 \pm 0.047$, and it increased to $1.63 \pm 0.044$ by stage 10.5 , a $10 \%$ change that was not significant at $P<0.09$. However, beginning at early stage 10.5 , the cells elongate in the mediolateral direction and align parallel to one another, parallel to the mediolateral axis and perpendicular to the prospective anterior-posterior axis, in a restricted arc, comprising the $\mathrm{VgAZ}$. The $\mathrm{VgAZ}$ spans the anterior (vegetal) end of the explant (Fig. 3C,D). Over the first 45 minutes of stage 10.5, the mean LWR of cells in the $\mathrm{VgAZ}$ increased by $34.4 \%$, from $1.63 \pm 0.044$ to $2.19 \pm 0.092$, a statistically significant change $(P<0.001)$. Finally, from early stage 11 to early stage 12 , the mean
LWR increased by $48 \%$ to $3.2 \pm 0.11$, which is again a significant change $(P<0.005)$. Thus the mean LWR rose sharply during stage 10.5 and continued to rise until at least stage 12 (Fig. 4, bottom panel), the endpoint of our analysis. Since the cells elongate mediolaterally, they also fall into parallel alignment with one another (Figs 3D; Figs 4 and 5, left, vegetal ends).

\section{(2) Mediolateral intercalation and convergence and extension}

As the mesodermal cells elongate and align, they begin to intercalate along the mediolateral axis, which results in a variable amount of convergence and extension. The amount of convergence and extension appears to be a function of whether the mediolaterally directed protrusive activity, described below, produces change in cell shape or produces intercalation of cells. As the cells elongate mediolaterally, they shorten in the anterior-posterior axis (Fig. 5). They also become taller and decrease their area in the plane of the explant (the surface viewed in Fig. 5) by about $30 \%$. Thus their change in shape tends to counter the effect of mediolateral intercalation (Fig. 5; also see Fig. 9). In explants that converged and extended very well, defined as more than doubling the length of their IMZs, the mean LWR of the mesodermal cells rose to only $2.15 \pm 0.09$. In explants that extended poorly, defined as those in which the IMZ extends less than half its original length, the mean LWR rises to $3.2 \pm 0.11$. In some explants that showed no convergence and extension, LWRs reach values of 5 to 6 , and at this point, many of the very elongated cells break loose at the large, anchoring protrusions at their medial or lateral ends (see below), and they quickly 'migrate' either laterally or medially, in the direction opposite to the end that loses traction. In these cases, the cells constantly exchange places along the mediolateral axis but do not converge or extend the tissue.

We estimated the efficiency of transforming mediolateral intercalation into extension by comparing the mediolateral intercalation index with the extension index. If the cells do not change shape, doubling their number in the anteriorposterior axis (mediolateral intercalation index of 2.0) should double the length of the array (extension index of 2.0). For the cell population represented in Fig. 4, bottom panel, the mediolateral intercalation index was 1.55 but the extension index was 1.06 and the area of the cells decreased by $31 \%$. The explant in Fig. 5 has a mediolateral intercalation index of 2.0 and an extension index of 1.39. We typically observed only $70 \%$ efficiency in translation of mediolateral intercalation into extension and little extension occurs until the mediolateral intercalation index exceeds 1.5. The loss of efficiency is due to cell shortening in the anterior-posterior direction and the decrease in surface area as the cells become taller (columnar).

\section{(3) The type and distribution of protrusive activity of FDX-labelled cells}

We examined the protrusive activity underlying the cell elongation, alignment and mediolateral intercalation described above, by using cells labelled with FDX and visualizing their behavior with low-light fluorescence microscopy, image processing and time-lapse video record- 

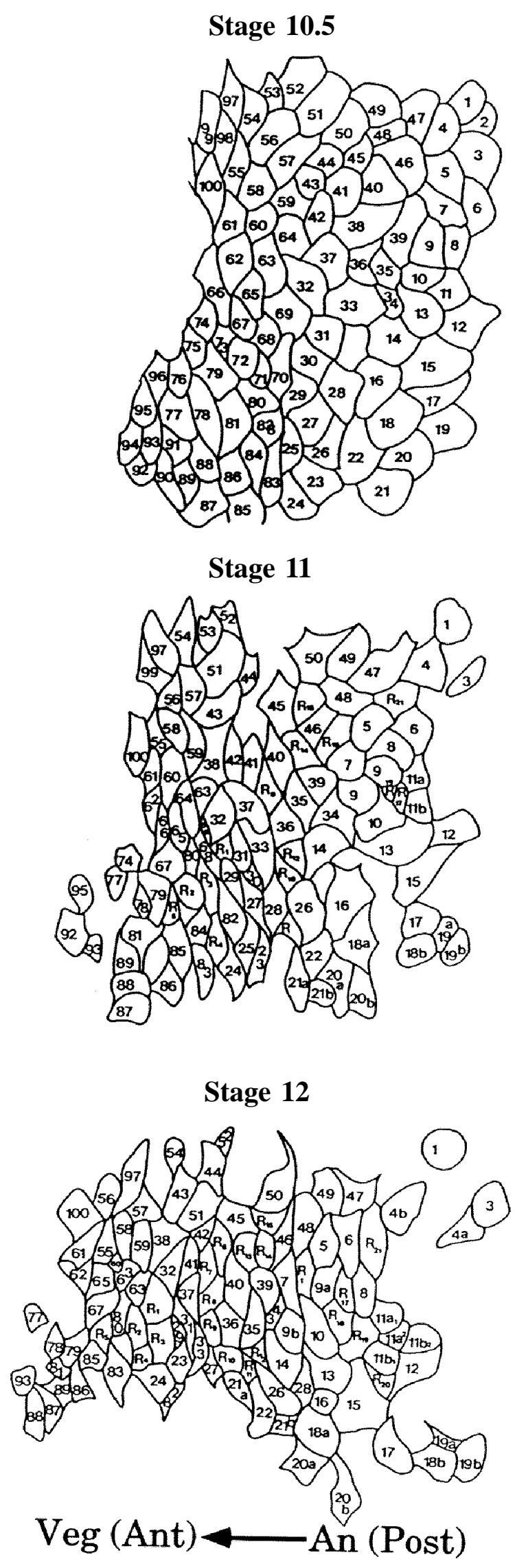

Fig. 5. Tracings from video recordings show the behavior of mesodermal cells in a shaved explant that showed convergence and extension at stages 10.5, 11 and 12. The vegetal (prospective anterior) end is to the left. Following individual, numbered cells show that mediolateral intercalation accounts for the convergence and extension. Cell division was infrequent ( 5 cells of 100 divided once, and one divided twice) and net radial intercalation was low ( 21 cells entered and 4 cells left the observed layer).

ing. We analyzed protrusive activity in periods from stage 10 to 10.25 , from stage 10.25 to 10.5 , and from stage 10.5 onward, since preliminary work indicated that these periods represent major transitions in cell behavior (Keller et al., 1991a,b). From stage 10 to 10.25 , protrusive activity consisted of small filiform and loboform protrusions (Fig. $6 \mathrm{~A}, \mathrm{~B})$, that are made frequently, averaging one new protrusion every 7 to 8 minutes, and are randomly distributed on all sides of the cells (Fig. 7, stage 10-10.25). In the next period, between stage 10.25 to stage 10.5 , protrusive activity was of generally the same type and frequency but biased slightly towards the medial and lateral ends of the cells (Fig. 7, stage 10.25-10.5). Beginning at stage 10.5, the onset of cell elongation, the protrusive activity became strongly bipolar, each cell making the majority of its new protrusions either medially or laterally (Fig. 6C,D; Fig. 7, stage 10.5-12). The frequency of new protrusions decreased to one every 28 minutes, due to the increased stability of those at the medial and lateral ends. These stabilized medial and lateral protrusions show continuous advance, and thus few 'new' protrusions were recorded by our criteria. Essentially no new protrusions formed on the anterior and posterior sides of the cells.

The polarized protrusive activity, directed medially and laterally, precedes and thus appears to be responsible for cell elongation, alignment and intercalation. The shape and movement of the cells appear to be a function of the activity of the large protrusions at the medial and lateral ends. Elongation is associated with increased protrusive and shortening with decline of protrusive activity. When cells translocate, the leading edge shows increased protrusive activity or the trailing edge shows declining activity. The active protrusions are applied to the surfaces of neighboring cells, and there is no evidence of contact inhibition of protrusive activity by these surfaces. The small filiform protrusions found on the anterior and posterior, elongated margins of the cells in SEMs (Keller et al., 1989b; Keller, 1984) do not appear as protrusive activity in recordings of explants, despite the fact that the finest filopodia can be seen with our methods. These may be generated by shrinkage during processing for SEM. In contrast, the large protrusions found on medial and lateral ends in recordings of explants match the morphology of the lamelliform and filiform protrusions seen at these sites in SEM of whole embryos (Keller et al., 1989b).

\section{Explants of the midgastrula dorsal mesoderm converge, extend and show mediolateral cell intercalation autonomously}

Although the protrusive activity described above appears directly related to mediolateral intercalation and the associated changes in cell shape, these events might result from 

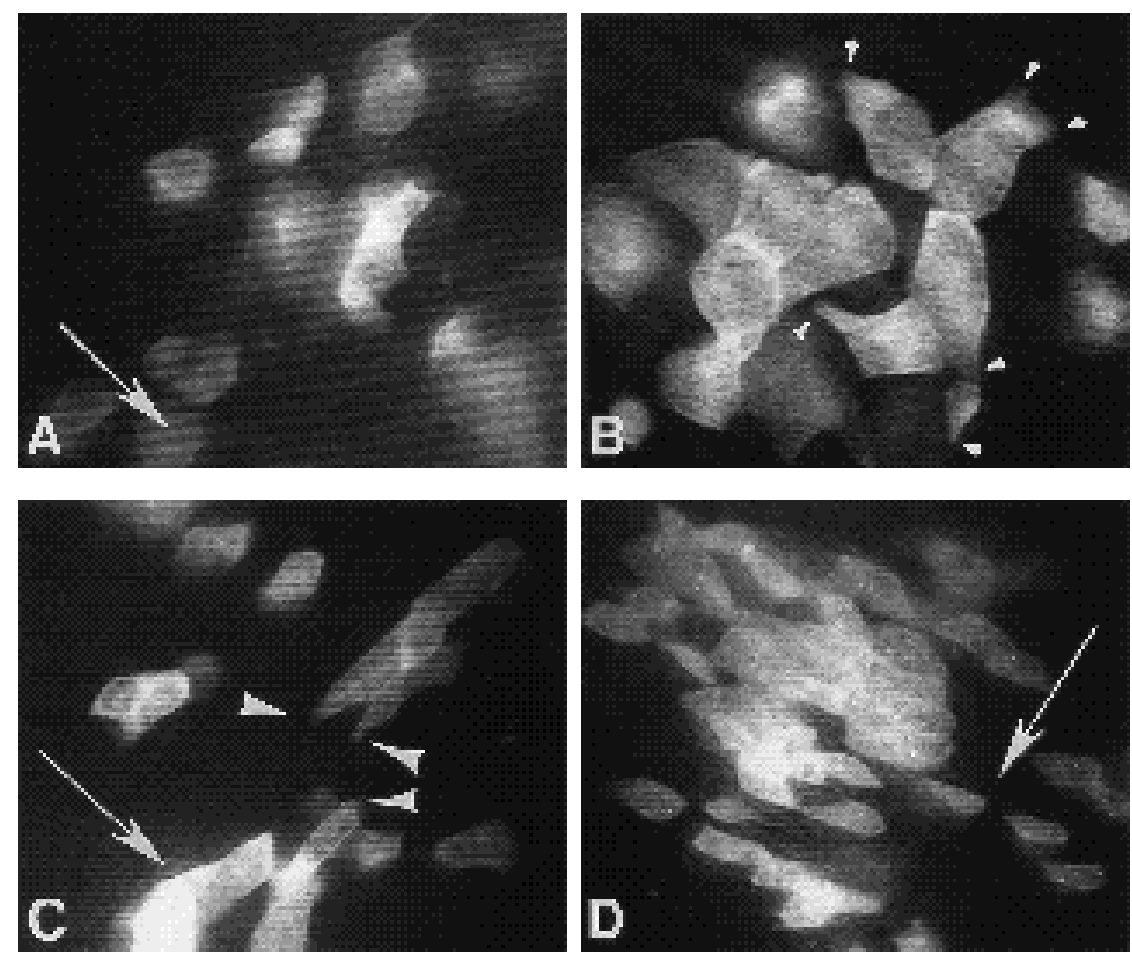

Fig. 6. Low-light fluorescence micrographs made from continuous time-lapse video recordings show protrusive activity of FDXlabelled deep mesodermal cells seeded into shaved explants of unlabelled cells. The arrow points from the posterior (animal end) to anterior (vegetal end) of the IMZ. The mesodermal cells are initially isodiametric and extend protrusions in all directions at stage 10 (A). Higher magnification shows the types of protrusions visible in low-light fluorescence recordings of labelled cells (pointers, B). By stage 10.5, the cells in the field shown in A begin showing bipolar protrusive activity, directed medially and laterally (pointers, C). At the same time the cells begin elongating, aligning and intercalating parallel to one another along the mediolateral axis (C). Elongation and alignment begin at the vegetal end of the explant, forming the vegetal alignment zone (VgAZ). The entire field of cells becomes elongated and aligned by stage 12 (D) and the medial cells participate in notochord formation, intercalating mediolaterally, parallel to the axis of cell elongation and transverse to the animal-vegetal axis. Magnification: A,B and C - 150×; D - 100×. some other, unseen motility, perhaps between the mesodermal cells or between them and the inner surface of the epithelial sheet. However, in explants consisting of only deep cells made at stage 10.5, the deep mesodermal cells express the MIB described above without the endodermal epithelium. These mesodermal cells elongate moderately, align parallel to one another and parallel to the mediolateral axis, and intercalate mediolaterally, thus producing convergence and extension (Fig. 8). Shaded pairs of cells (numbers 44 and 30,11 and 9,14 and 57, Fig. 8) become separated along the mediolateral axis by cells intercalating from both sides (Fig. 8), doubling length of the anteriorposterior axis 7 hours later (stage 17). The notochordalsomitic boundaries form and the anterior-posterior and lateral-medial progressions of cell behaviors seen in shaved explants (see Shih and Keller, 1992b) are displayed. The dorsal mesoderm has already thinned by radial intercalation

Fig. 7. The distribution of protrusive activity visible in low-light fluorescence video recordings of FDX-labelled chordamesoderm cells seeded in shaved explants is shown graphically by plotting number of protrusions occurring in 20 degree sectors around the cell, with 90 and 270 degrees (marked with pointers) representing the medial and lateral aspects of the explant. Between stages 10 and 10.25 ( 1 hour), protrusions are made at the rate of one every 7-8 minutes., and are evenly distributed around the cell periphery. Between stage 10.25 and stage 10.5 ( 1 hour), protrusive activity becomes biased toward the medial and lateral sides of the cells. This bias precedes conspicuous cell elongation and alignment. From stage 10.5 to 12 (2 hours), protrusive activity is stabilized with new protrusions forming every 30 minutes, and all protrusions are highly localized, being restricted almost entirely to the medial and lateral ends of the cells.

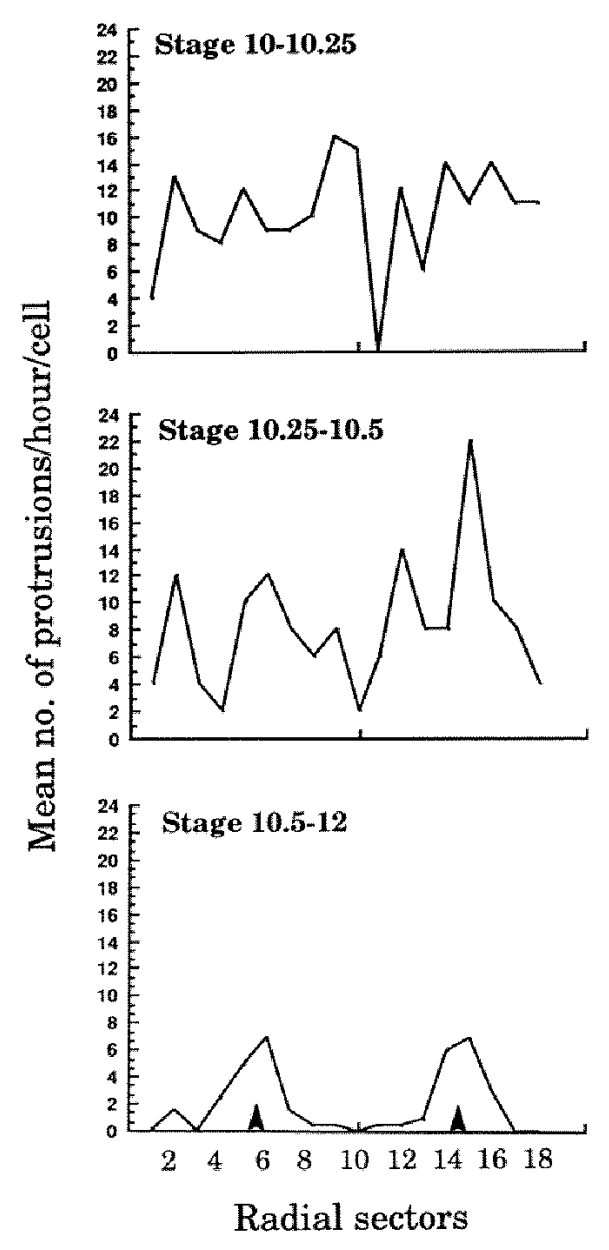




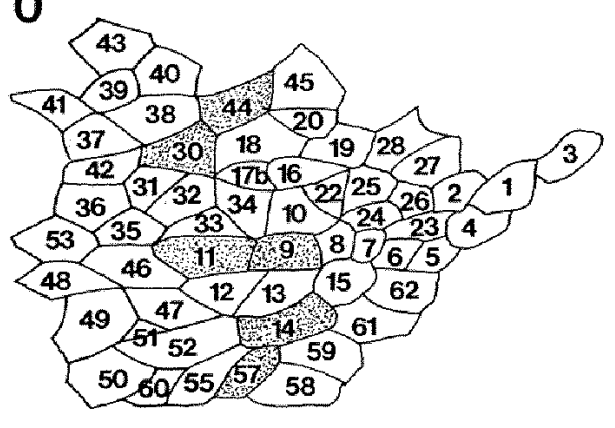

\section{1:22}

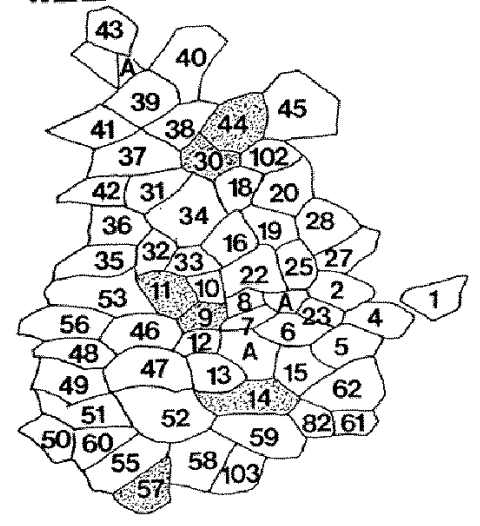

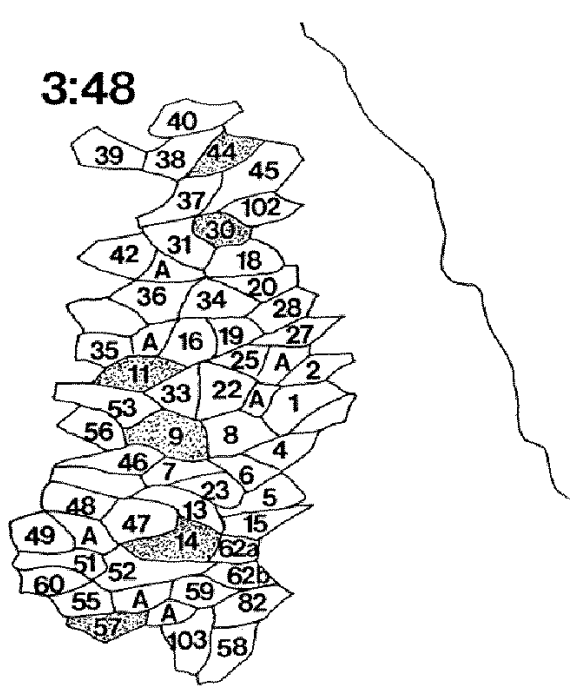

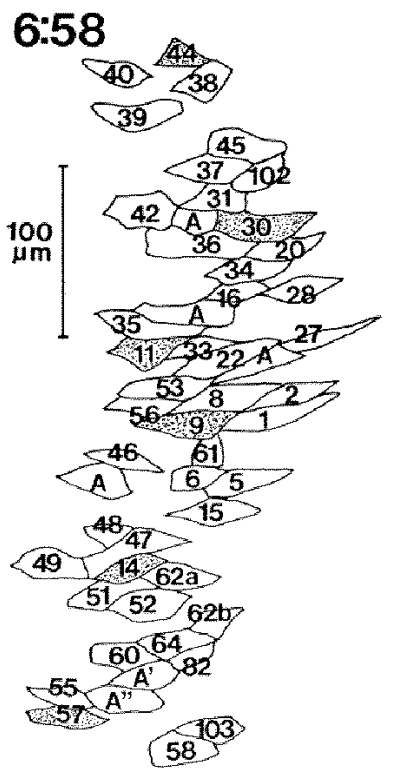

Fig. 8. Tracings of cells from a video recording of the development of a deep cell explant of the DMZ of the midgastrula (stage 10.5) show the mediolateral cell intercalation bringing about convergence and extension of the mesoderm. Note the separation of the shaded cell pairs along the anterior-posterior axis (vertical in the figure) and the intercalation of cells between them from both sides. The vegetal end of the explant is at the top in all figures. Newly appearing cells are indicated by an ' $\mathrm{A}$ ' and division products are designated ' $a$ ' and ' $b$ '.
(Wilson and Keller, 1991) to less than two layers, and it is reduced to essentially one layer as the intercalating cells become taller and occupy the full thickness of the explant. Occasional gaps between the cells reveal no deeper layer of cells. Thus we have reduced the system to essentially one layer of mesodermal cells, and the MIB observed among these cells is the only protrusive activity to which mediolateral intercalation and convergence and extension can be attributed.

\section{Discussion}

The mechanism of mediolateral intercalation

The mesodermal cell behavior in the shaved and deep cell explants described above enable us to settle many issues previously raised about the mechanism of mediolateral intercalation (Keller et al., 1985a,b, 1991a,b; Keller and Hardin, 1987) and to refine our understanding of this process.

\section{(1) The cellular basis of convergence and extension: $M I B$}

The complex of motile behaviors associated with mediolateral intercalation is summarized in Fig. 9: (1) in the early midgastrula, the multipolar, rapid protrusive activity slows and becomes directed medially and laterally, such that the cells become bipolar; (2) the cells extend protrusions medially and laterally between one another; (3) these protrusions are closely applied to the surfaces of adjacent mesodermal cells and are not contact inhibited by these surfaces; (4) the mesodermal cells appear to exert traction on one another, using these protrusions; (5) as a result, the cells elongate, align parallel to one another and parallel to the mediolateral axis; (6) they intercalate along the mediolateral axis, thus producing convergence and extension. Cell behavior observed in the multilayered explants used previously could have been passive, with the active, force-producing motility occurring in an unseen layer. However, the shaved explant has only an endodermal epithelial layer, which previous work suggests is mechanically passive (reviewed in 

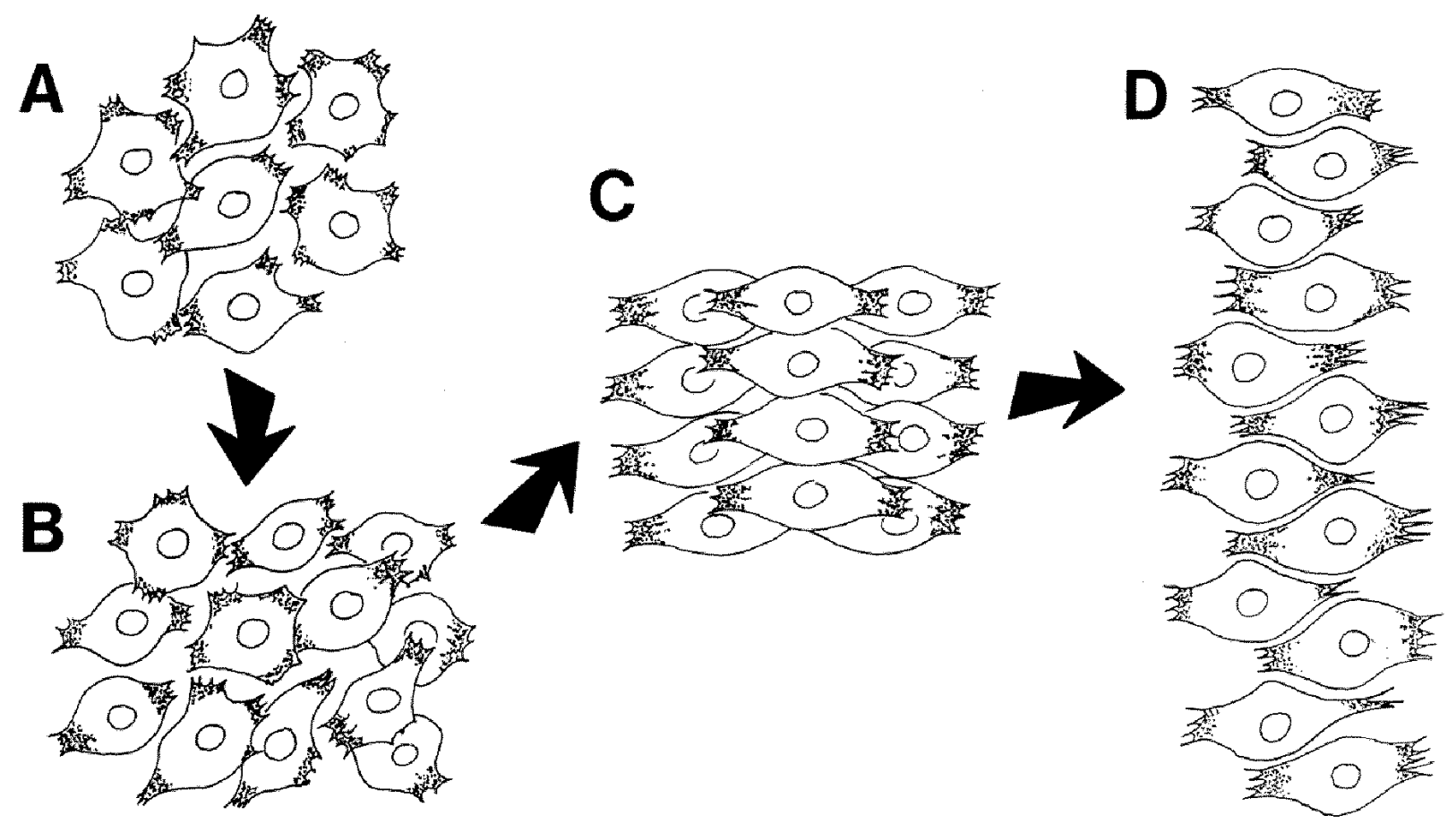

Fig. 9. A schematic diagram summarizes the protrusive activity of deep mesodermal cells that drives their mediolateral intercalation. In the early gastrula stages, cells make and withdraw protrusions rapidly in all directions and remain isodiametric while undergoing one round of division (A,B). Radial intercalation normally occurs in the embryo and in multilayered explants during this period. From stage 10.25 to early 10.5 , protrusive activity is progressively restricted to medial and lateral sides of the cells; the cells begin to elongate in the mediolateral direction and thus become aligned parallel to one another (B,C). From stage 10.5 onward, the rate of formation of new protrusions declines, and existing protrusions on the medial and lateral ends are stable, exerting traction on adjacent mesodermal cells, thus bringing about their mediolateral intercalation (C,D).

Keller et al., 1991b; Keller and Winklbauer, 1992) and as few as one layer of deep cells, but yet it converges and extends. Moreover, the deep cell explants show that mesoderm cells alone, without the endodermal epithelium, can converge and extend. Since MIB is the only motility displayed by these mesodermal cells, we conclude that this behavior drives the mediolateral elongation, alignment and cell intercalation producing convergence and extension of the mesodermal cell population.

This conclusion is supported by several other observations. First, bipolar protrusive activity precedes and is spatially and temporally correlated, on an individual cell basis, with mediolateral elongation, alignment and intercalation. Temporary loss of traction or protrusive activity at one end of the cell results in retraction of that end of the cell or movement of the cell in the opposite direction. This shows a direct relationship between protrusive activity, cell shape and cell movement. Second, when convergence and extension are retarded or prevented by greater coverslip pressure, the deep cells display vigorous protrusive activity medially and laterally and pull their ends along one another's surfaces, but instead of intercalating they elongate excessively in the mediolateral axis and shorten excessively in the anterior-posterior axis. Often they break loose from adjacent cells on one end or the other, presumably because tension in the cell exceeds the strength of their anchorage, and migrate rapidly laterally or medially, exchanging mediolat- eral positions with one another without producing convergence and extension. These behaviors suggest that the degree of cell elongation should be directly proportional to the amount of mechanical resistance offered to the explant and inversely proportional to the amount of convergence and extension, a hypothesis that we are currently testing.

\section{(2) Oriented protrusive activity elongates and aligns cells at the same time}

Setting up the parallel arrays of cells in the axis of mediolateral intercalation is a single-step process arising directly from the initial bias of protrusive activity in the medial and lateral directions. Thus cells become aligned parallel to one another and to the mediolateral axis as they elongate. Cells do not appear to elongate in all directions and then align by contact interactions as previously suggested (see Keller et al., 1991b; Weliky et al., 1992). Since MIB is expressed only by interaction of mesodermal cells with one another, rather than with an external substratum, we do not know when, if ever, the bipolar protrusive activity or the elongate cell shapes become autonomous properties of the individual cells or how these behaviors are related to several kinds of polarity seen among individual, cultured mesodermal cells (Nakatsuji and Johnson, 1983; Winklbauer, 1990; Winklbauer and Nagel, 1991). 
(3) Cell traction must be balanced (of equal magnitude) in medial and lateral directions to produce the type of mediolateral intercalation essential for convergence and extension

Cell traction appears to be roughly balanced in the medial and lateral directions, and the entire population narrows and lengthens as the cells slowly and progressively creep between one another in uniform fashion. The intercalating cells form arcs, ending on each side at the vegetal edge of the explant, which is normally attached to the vegetal endoderm. In the embryo, convergence and extension as well as involution are produced by shortening these arcs (see Shih and Keller, 1992b; Keller et al., 1992c). If protrusive activity and traction become unbalanced in favor of the medial or lateral direction, the cell migrates medially or laterally while its neighbors do likewise, and thus cells exchange mediolateral positions without producing convergence or extension. Note also that convergence is not a matter of directional cell migration toward the dorsal midline but a matter of shortening continuous arcs of cells that are anchored at each end in the vegetal endoderm (see Shih and Keller, 1992b; Keller et al., 1992c).

\section{(4) Traction is exerted on adjacent mesodermal cell} surfaces without contact inhibition of protrusive activity

The major medial and lateral protrusions appear to be applied directly to the surfaces of other mesodermal cells, as seen in the video recordings described here and in SEMs of the same cells in embryos (see Keller et al., 1989b) and in explants (Keller, R., unpublished work). Video recordings show no contact inhibition of protrusive activity (see Abercrombie, 1970) by these surfaces. Intercalation in thicker explants or whole embryos could involve traction of deep mesodermal cells on the underside of the overlying epithelium (Keller et al., 1991a,b), but the explants of deep mesodermal cells show that traction only among deep cells is sufficient to produce mediolateral intercalation and convergence and extension.

\section{(5) Cells appear to wedge between one another rather than moving into previously opened spaces (see Keller et al., 1985a,b; Keller and Hardin, 1987)}

Nearly all intercalation occurs by cells wedging between what appear to be closely apposed neighbors. The same was observed in notochords of teleost fish (Thorogood and Wood, 1987), ascidians (Miyamoto and Crowther, 1985) and Xenopus (Keller and Hardin, 1987; Keller and et al., 1989a). This observation does not necessarily mean that cells 'push' between one another; small fluctuations of the cells surfaces may open up very small spaces, allowing the invasion of lamellipodia, which could then pull the cells between one another (see Welicky et al., 1992).

\section{(6) The bipolar mechanism of mediolateral intercalation described here is modified to a monopolar mechanism by the notochord-somite boundary (Keller et al., 1989a)}

When the notochord-somite boundary forms, the internal, bipolar cells change to a monopolar activity on contact with the boundary. The surfaces of the cells entering the boundary region cease the intercalatory, invasive activity and make stable filiform protrusions overlapping other boundary cells. This results in the 'capture' of any internal cell touching the boundary (Keller et al., 1989a). Meanwhile, protrusive activity continues at the opposite, internal end of the boundary cells, which pulls more internal cells into the boundary (Keller et al, 1989a; Weliky et al., 1992; Keller and Shih, 1991b). The boundary elongates because more cells are added to the boundary than leave it. This mechanism of boundary elongation was proposed some time ago to explain notoplate-neural plate elongation (Jacobson et al., 1986; also see Jacobson and Gordon, 1976; Jacobson, 1981).

\section{Comparison of cell behavior in explants and whole embryos}

Cell behavior in explants reflects normal morphogenetic processes in whole embryos. The data on cell division are consistent among the three types of explants (cf. Wilson and Keller, 1991) and, though little is known of cell division patterns in the deep IMZ in vivo, our results are consistent with those of Bragg (1938) on Bufo. The data on radial intercalation are likewise consistent, with radial intercalation occurring in the first half of gastrulation in shaved explants, in standard explants (Wilson and Keller, 1991) and in whole embryos (Keller, 1980; Keller et al., 1992a). In all three types of explants, convergence and extension occur primarily by mediolateral cell intercalation, as in vivo (Keller and Tibbetts, 1989). The elongate cell shapes, the mediolateral alignment, and the detailed morphology of the cells and their protrusions seen in video recordings of explants appear in SEMs of the same cells in whole embryos (Keller, 1984; Keller et al., 1989b). Shaved and deep cell explants extend less than other explants, but this is expected, since they have fewer deep cells to drive convergence and extension but the same surface area and friction against the restraining culture chamber.

Similarities and contrasts with teleost deep cells; variations on a theme

Deep cells of the teleost embryo first undergo radial and then mediolateral intercalations as they converge on the dorsal midline and extend to form the embryonic shield (Warga and Kimmel, 1990), but the details of intercalation may be different from Xenopus. In contrast to the bipolarity of their Xenopus equivalents, deep cells in Fundulus converge dorsally by dorsally directed protrusive activity, using filo-lamellipodia or by blebbing (Trinkaus et al., 1991, 1992). Unlike the Xenopus cells, the Fundulus cells that move by filo-lamellipodia are contact inhibited and intercalate only as spaces open up, whereas those that move by blebbing are not contact inhibited and intercalate without prior opening of spaces (Trinkaus et al., 1992). The directed, dorsal migration does not appear to produce a constriction ring in Fundulus. In contrast, in Xenopus, mediolateral intercalation along arcs, anchored at each end in the vegetal endoderm, forms arcs of constriction across the IMZ that drive involution and constrict the blastoporal lips around the yolk plug (see Keller et al., 1992c; Keller, 1986; Wilson and Keller, 1991; Shih and Keller, 1992b; Keller and Jansa, 1992). 


\section{The role of patterned cell division}

Although patterns of cell division have been described in early amphibian development (Bragg, 1938; Dettlaff, 1964; Graham and Morgan, 1966; Hara, 1977; Kageyama, 1987; Satoh, 1977), cell division is not thought to have a direct role in gastrulation (Holtfreter, 1943; Cooke, 1973). In Xenopus laevis, division of axial mesodermal cells is correlated with radial intercalation early in gastrulation. These cells rarely divide during late gastrulation and neurulation, as seen here and previously (Wilson and Keller, 1991). Cell division could be causally related to radial intercalation. Alternatively, cell division may be incompatible with subsequent mediolateral intercalation, since rounding up and dividing may not allow cells to polarize their protrusive activity, elongate, align and crawl between one another. Foe (1989) has proposed that mitotic domains in Drosophila regulate mitosis to occur at specific times and thus it does not interfere with morphogenetic events that occur at other times. Since mediolateral intercalation appears to require continuous arcs of cells with polarized protrusive activity, it may not occur if at any time a significant fraction of the population was rounded up to undergo cytokinesis. Thus the converging and extending mesoderm of Xenopus may constitute a 'mitotic domain' in which division of all or most cells is regulated to occur just prior to expression of MIB.

This work was supported by NSF grant DCB89052 and NIH grant HD25594. We thank J. P. Trinkaus for his inspiration, encouragement, and pioneering work in morphogenesis. We also thank Paul Wilson for his pointed criticism and support. Finally, we thank Jessica Bolker, Mary Constance Lane, Susan Purcell, Amy Sater and Barbara Stebbins for their insightful comments and suggestions.

\section{References}

Abercrombie, M. (1970). Contact inhibition in tissue culture. In vitro 6, 128-142.

Bragg, A. N. (1938). The organization of the early embryo of Bufo Cognatus as revealed especially by the mitotic index. Z. Zellforsch. Mikrosk. Anat. 28, 154-178.

Cooke, J. (1973). Properties of the primary organization field in the embryo of Xenopus laevis IV. Pattern formation and regulation following early inhibition of mitosis. J. Embryol. Exp. Morph. 30, 49-62.

Dettlaff, T. (1964). Cell division, duration of interkinetic states, and differentiation in early stages of embryonic development. Adv. Morph. 3, 323-360.

Foe, V. (1989). Mitotic domains reveal early commitment of cells in Drosophila embryos. Development 107, 1-22.

Gimlich, R. L. and Braun, J. (1985). Improved fluorescent compounds for tracing cell lineage. Dev. Biol. 109, 509-514.

Graham, C. and Morgan, R. (1966). Changes in the cell cycle during early amphibian development. Dev. Biol. 14, 439-460.

Hara, K. (1977). The cleavage pattern of the axolotl egg studied by cinematography and cell counting. Wilhelm Roux Arch. Dev. Biol. 181, 73-87.

Holtfreter, J. (1943). A study of the mechanics of gastrulation. Part I. J. Exp. Zool. 94, 261-318.

Ikushima, N. and Maruyama, S. (1971). Structure and developmental tendency of the dorsal marginal zone in the early amphibian gastrula. $J$. Embryol. Exp. Morph. 25, 263-276.

Jacobson, A. and Gordon R. (1976). Changes in the shape of the developing vertebrate nervous system analyzed experimentally, mathematically, and by computer simulation. J. Exp. Zool. 197, 191-246.

Jacobson, A. (1981). Morphogenesis of the neural plate and tube. In
Morphogenesis and Pattern Formation (ed. T. G. Connolly, L. Brinkley and B. Carlson) pp. 223-263. New York: Raven Press.

Jacobson A., Oster, G., Odell, G. and Cheng, L. (1986). Neurulation and the cortical tractor model for epithelial folding. J. Embryol. Exp. Morph. 96, $19-49$.

Kageyama, T. (1987). Mitotic behavior and pseudopodial activity of cells in the embryo of Oryzias latipes during blastula and gastrula stages. $J$. Exp. Zool. 244, 243-252.

Kay, B. and Peng, B., eds. (1991) Methods in Cell Biology, Vol. 36: Xenopus laevis: Practical Uses in Cell and Molecular Biology. New York: Academic Press.

Keller, R. E. (1975). Vital dye mapping of the gastrula and neurula of Xenopus laevis. I. Prospective areas and morphogenetic movements of the superficial layer. Dev. Biol. 42, 222-241.

Keller, R. E. (1976). Vital dye mapping of the gastrula and neurula of Xenopus laevis. II. Prospective areas and morphogenetic movements of the deep layer.Dev. Biol. 51, 118-137.

Keller, R. E. (1980). The cellular basis of epiboly: An SEM study of deepcell rearrangement during gastrulation in Xenopus laevis. J. Embryol. Exp. Morph. 60, 201-234.

Keller, R. E. (1984). The cellular basis of gastrulation in Xenopus laevis: active post-involution convergence and extension by mediolateral interdigitation. Am. Zool. 24, 589-603.

Keller, R. E. (1986). The cellular basis of amphibian gastrulation. In Developmental Biology: A Comprehensive Synthesis. Vol. 2. The Cellular Basis of Morphogenesis. (ed. L. Browder) New York: Plenum Press.

Keller, R. E. (1987). Cell rearrangement in morphogenesis. Zool. Sci. 4, 763-779.

Keller, R. E. (1991). Early embryonic development of Xenopus laevis. In Methods in Cell Biology, Vol. 36: Xenopus laevis: Practical Uses in Cell and Molecular Biology (ed. B. Kay, and H.B. Peng), Chapter 5, pp. 61113. New York: Academic Press.

Keller, R. E., Danilchik, M., Gimlich, R. and Shih, J. (1985a). Convergent extension by cell intercalation during gastrulation of Xenopus laevis. In Molecular Determinants of Animal Form (ed. G. M. Edelman), pp. 111-141. New York: Alan R. Liss, Inc.

Keller, R. E., Danilchik, M., Gimlich, R. and Shih, J. (1985b). The function of convergent extension during gastrulation of Xenopus laevis. J. Embryol. Exp. Morph. 89 Supplement, 185-209.

Keller, R. E. and Hardin, J. D. (1987). Cell behavior during active cell rearrangement: evidence and speculations. J. Cell Sci. Supplement 8, 369393.

Keller, R. E. and Danilchik, M. (1988). Regional expression, pattern and timing of convergence and extension during gastrulation of Xenopus laevis. Development 103, 193-210.

Keller, R. E. and Tibbetts, P. (1989). Mediolateral cell intercalation in the dorsal axial mesoderm of Xenopuslaevis.Dev. Biol. 131, 539-549.

Keller, R., Cooper, M. S., Danilchik, M., Tibbetts, P. and Wilson, P. A. (1989a). Cell intercalation during notochord development in Xenopus laevis. J. Exp. Zool. 251, 134-154.

Keller, R. E., Shih, J. and Wilson, P. A. (1989b) Morphological polarity of intercalating deep mesodermal cells in the organiser of Xenopus laevis gastrulae, Proceedings of the 47th annual meeting of the Electron Microscopy Society of America. p. 840. San Francisco Press.

Keller, R., Shih, J. and Wilson, P. (1991a). Cell motility, control and function of convergence and extension during gastrulation in Xenopus. In Gastrulation: Movements, Patterns, and Molecules (ed. R. Keller, F. Griffin, and W. Clark), pp. 101-119, New York: Plenum Press.

Keller, R., Shih, J., Wilson, P., and Sater, A. (1991b). Pattern and function of cell motility and cell interactions during convergence and extension in Xenopus. In Cell-Cell Interactions in Early Development, (ed. J. Gerhart) 49th Symp. Soc. Dev. Biol., pp. 31-62. New York: Wiley-Liss, Inc.

Keller, R. E., Shih, J. and Sater, A. K. (1992a). The cellular basis of the convergence and extension of the Xenopus neural plate. Dev. Dynamics, 193(3), 199-217.

Keller, R. E., Shih, J., Sater, A. K. and Moreno, C. (1992b). Planar induction of convergence and extension of the neural plate by the organizer of Xenopus. Dev. Dynamics 193, 218-234.

Keller, R. E., Shih, J. and Domingo, C. (1992c) The patterning and functioning of protrusive activity during convergence and extension of the Xenopus organiser. Development 1992 Supplement, 81-91.

Keller, R. and Winklbauer, R. (1992). The cellular basis of amphibian gastrulation. In Current Topics in Developmental Biology, (ed. R. Pedersen) in press. 
Keller, R. and Jansa, S. (1992). Xenopus gastrulation in absence of the blastocoel roof. Submitted.

Kintner, C. R. and Brockes, J. P. (1984). Monoclonal antibodies identify blastemal cells derived from dedifferentiating muscle in newt limb regeneration. Nature 308, 67-69.

Mishell, B. B. and Shiigi, S. M. (1980). Appendex A. Selected Methods in Cellular Immunology. San Francisco: W. H. Freeman and Company.

Miyamoto, D. M. and Crowther, R. (1985). Formation of the notochord in living ascidian embryos. J. Embryol. Exp. Morph.86, 1-17.

Nakatsuji, N. and Johnson, K. (1983). Cell locomotion in vitro by Xenopus laevis gastrula mesodermal cells. J. Cell Sci. 59, 43-60.

Satoh, N. (1977).'Metachronous' cleavage and initiation of gastrulation in amphibian embryos. Dev., Growth Differ. 19, 111-117.

Schechtman, A. M. (1942). The mechanics of amphibian gastrulation. I. Gastrulation-producing interactions between various regions of an anuran egg (Hyla regilia). Univ. Calif. Publ. Zool. 51, 1-39.

Schoenwolf, G. C. and Alvarez, I. C. (1989). Roles of neuroepithelial cell rearrangement and division in shaping the avian neural plate. Development 106, 427-439.

Shih, J. and Keller, R. (1992a) The epithelium of the dorsal marginal zone of Xenopus has organizer properties. Development 116, $\mathrm{xx}-\mathrm{xx}$.

Shih, J. and Keller, R. (1992b). Patterns of cell motility in the organizer and dorsal mesoderm ofXenopus. Development 116, xx-Xx.

Spemann, H. (1938). Embryonic Development and Induction. New York: Yale University Press.

Thorogood, P. and Wood, A. (1987). Analysis of in vivo cell movement using transparent tissue systems.J. Cell Sci. Supplement 8, 395-413.

Trinkaus, J. P., Trinkaus, M. and Fink, R. (1991) In vivo analysis of convergent cell movements in the germ ring of Fundulus. In Gastrulation: Movements, Patterns, and Molecules (ed. R. Keller, F. Griffin, and W. Clark), pp. 121-134, New York: Plenum Press.

Trinkaus, J. P., Trinkaus, M. and Fink, R. (1992). On the convergent cell movements of gastrulation in Fundulus.J. Exp. Zool. 261, 40-61.

Vogt, W. (1929). Gestaltanalyse am Amphibienkein mit ortlicher Vitalfarbung. II.Teil. Gastrulation und Mesodermbildung bei Urodelen und Anuren. Wilhelm Roux Arch. EntwMech. Org. 120, 384-706.

Warga, R. and Kimmel, C. (1990). Cell movements during epiboly and gastrulation in zebrafish. Development 108, 569-580.

Weliky, M., Minsuk, S., Keller, R. and Oster, G. (1992). Notochord morphogenesis in Xenopus laevis: simulation of behavior underlying tissue convergence and extension. Development 113, 1231-1244.

Wilson, P. (1990). The development of axial mesoderm in Xenopuslaevis. Ph.D. dissertation, University of California, Berkeley.

Wilson, P. A., Oster, G. and Keller, R. (1989). Cell rearrangement and segmentation in Xenopus: direct observation of cultured explants. Development 105, 155-166.

Wilson, P. and Keller, R. (1991). Cell rearrangement during gastrulation of Xenopus: direct observation of cultured explants. Development 112, 289300.

Winklbauer, R. (1990). Mesodermal cell migration during Xenopus gastrulation. Dev Biol.142,155-168.

Winklbauer, R. and Nagel, M. (1991). Directional mesoderm cell migration in the Xenopus gastrula. Dev. Biol. 148, 573-589.

(Accepted 28 August 1992) 